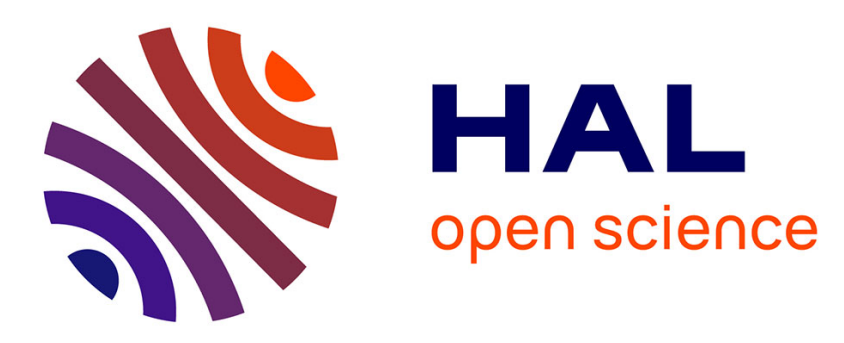

\title{
Understanding and Tuning the Catalytic Bias of Hydrogenase
}

\author{
Abbas Abou Hamdan, Sébastien Dementin, Pierre-Pol Liebgott, Oscar \\ Gutiérrez-Sanz, Pierre Richaud, Antonio L de Lacey, Marc Rousset, Patrick \\ Bertrand, Laurent Cournac, Christophe Léger
}

\section{To cite this version:}

Abbas Abou Hamdan, Sébastien Dementin, Pierre-Pol Liebgott, Oscar Gutiérrez-Sanz, Pierre Richaud, et al.. Understanding and Tuning the Catalytic Bias of Hydrogenase. Journal of the American Chemical Society, 2012, 134 (20), pp.8368-8371. 10.1021/ja301802r . hal-01977597

\section{HAL Id: hal-01977597 https://hal.science/hal-01977597}

Submitted on 22 Jul 2019

HAL is a multi-disciplinary open access archive for the deposit and dissemination of scientific research documents, whether they are published or not. The documents may come from teaching and research institutions in France or abroad, or from public or private research centers.
L'archive ouverte pluridisciplinaire HAL, est destinée au dépôt et à la diffusion de documents scientifiques de niveau recherche, publiés ou non, émanant des établissements d'enseignement et de recherche français ou étrangers, des laboratoires publics ou privés. 


\title{
Understanding and tuning the catalytic bias of hydrogenase
}

\author{
Abbas Abou Hamdan, ${ }^{a}$ Sébastien Dementin, ${ }^{\text {a }}$ Pierre-Pol Liebgott, ${ }^{a}$ Oscar Gutierrez-Sanz, ${ }^{\mathrm{b}}$ Pierre Ri- \\ chaud, ${ }^{\mathrm{c}}$ Antonio L. De Lacey, ${ }^{\mathrm{b}}$ Marc Rousset, ${ }^{\mathrm{a}}$ Patrick Bertrand, ${ }^{\mathrm{a}}$ Laurent Cournac, ${ }^{\mathrm{c} *}$ and Christophe \\ Léger. ${ }^{a *}$
}

(a) Laboratoire de Bioénergétique et Ingénierie des Protéines, Institut de Microbiologie de la Méditerranée, CNRS and AixMarseille Université. 31 chemin Joseph Aiguier, 13402 Marseille Cedex 20, France. (b) Instituto de Catalisis y Petroleoquimica (CSIC), 28049 Madrid, Spain (c) CEA, DSV, IBEB, Laboratoire de Bioénergétique et Biotechnologie des Bactéries \& Microalgues, Saint Paul Lez Durance / CNRS, UMR Biologie Végétale \& Microbiologie Environnementales, Saint Paul lez Durance, France / Aix-Marseille Université, Saint Paul lez Durance, France.

\begin{abstract}
When enzymes are optimized for biotechnological purposes, the goal often is to increase stability or catalytic efficiency. However, many enzymes reversibly convert their substrate and product, and if one is interested in catalysis in only one direction, it may be necessary to prevent the reverse reaction. In other cases, reversibility may be advantageous because only an enzyme that can operate in both directions can turn-over at a high rate even under conditions of low thermodynamic driving force. Therefore, understanding the basic mechanisms of reversibility in complex enzymes should help the rational engineering of these proteins. Here, we focus on NiFe hydrogenase, an enzyme that catalyses $\mathrm{H}_{2}$ oxidation and production, and we elucidate the mechanism that governs the catalytic bias (the ratio of maximal rates in the two directions). Unexpectedly, we found that this bias is not mainly determined by redox properties of the active site, but rather by steps which occur on sites of the proteins that are remote from the active site. We evidence a novel strategy for tuning the catalytic bias of an oxidoreductase, which consists in modulating the rate of a step that is limiting only in one direction of the reaction, without modifying the properties of the active site.
\end{abstract}

The four Michaelis parameters (two maximal rates and two values of $K_{\mathrm{m}}$ ) which characterize the forward and reverse reactions of a one-substrate one-product enzyme are related to each other and to the equilibrium constant of the reaction by the Haldane equation. ${ }^{1}$ The forward and reverse maximal rates sometimes differ so much that certain enzymes were designated as "one-way enzymes". ${ }^{2}$ The origin of such kinetic asymmetry, referred to as "catalytic bias", has rarely been investigated. Jencks proposed that directionality may result from the destabilization of the enzyme-substrate complex, which would decrease the energy required to reach the transition state in the forward direction. ${ }^{2}$ This "Circe effect" is controversial $^{3}$ and has found no echo in the case of oxidoreductases, whose directionality is always discussed by comparing the potential of the substrate/product redox couple with the potential of either the active site or the redox centers of the electron transfer (ET) chain, when there is one (see examples in supplementary information).
In trying to explain the catalytic bias from a single property of the enzyme (the potential of either the active site or the ET chain), one implicitly assumes that a single redox step, ET either between the substrate and the active site or to/from an electron relay, determines both maximal rates. However, the catalytic cycle of oxidoreductases involves various steps (substrate binding, product release, proton and electron transfers, active-site chemistry) and it may occur that the rate limiting step (rls) is not the same when the enzyme works forward or backward. Two different steps may define the two maximal rates, and their ratio. Demonstrating that this can occur requires that the rls be defined in both directions in a series of variants that exhibit different catalytic preferences. Hereafter, we do so by characterizing a series of Desulfovibrio fructosovorans $(D f) \mathrm{NiFe}$ hydrogenase mutants. Previously, we have shown that the WT enzyme catalyzes $\mathrm{H}_{2}$ production and oxidation at similar maximal rates, and that narrowing the substrate channel using site directed mutagenesis has no effect on the maximal rate of $\mathrm{H}_{2}$ oxidation. 4,5 Here we show that these mutations slow $\mathrm{H}_{2}$ production up to 100-fold. In redox titrations, the active site of the mutants that have little reductive activity behaves like in the WT enzyme. We use a novel method based on the isotope-exchange assay to determine the rates of $\mathrm{H}_{2}$ release from the active site to the solvent, and we conclude that this step limits $\mathrm{H}_{2}$ production whereas $\mathrm{H}_{2}$ entry does not determine the maximal rate of $\mathrm{H}_{2}$ oxidation. Conversely, the previous observation 5 that modifying the electron transfer chain selectively slows $\mathrm{H}_{2}$ oxidation shows that electron transfer limits the rate of $\mathrm{H}_{2}$ oxidation but not $\mathrm{H}_{2}$ production. ${ }^{6}$ This is the first demonstration, on a specific example, that slowing a step that is rate limiting only when the enzyme works in one direction is a general mechanism for biasing the enzyme in the other direction, independently of the redox properties of the cofactors.

We prepared the enzyme samples as described previously. $\mathrm{H}_{2}$ oxidation rates were measured using a spectrophotometric assay at $\mathrm{pH} 8,30^{\circ} \mathrm{C}$, with $50 \mathrm{mM}$ oxidized methyl viologen (MV), under one atm. of $\mathrm{H}_{2 .} .5$ The $K_{\mathrm{m}}$ for $\mathrm{H}_{2}$ were measured electrochemically. 5 The voltammograms in fig 2 were obtained with the enzyme bound to a rotating graphite electrode. ${ }^{7} \mathrm{H}_{2}$ production was followed using mass spectrometry (MS), in a solution initially saturated with $\mathrm{Ar}$, with a saturating concentration of re- 
duced MV (2mM) at $\mathrm{pH} 7.2,30^{\circ} \mathrm{C}$; since $\mathrm{H}_{2}$ inhibits $\mathrm{H}_{2-}$ production by $\mathrm{NiFe}$ hydrogenases, ${ }^{8}$ we extrapolated the initial rates using a plot of $1 /$ rate against $1 /\left[\mathrm{H}_{2}\right]$. We performed the $\mathrm{H}^{+} / \mathrm{D}^{+}$exchange experiments at $\mathrm{pH}$ 7.2, $30^{\circ} \mathrm{C}, 4$ and FTIR titrations at $\mathrm{pH} 8.9$

Previous investigations using crystallography and molecular dynamics have predicted that a network of hydrophobic channels guides $\mathrm{H}_{2}$ to/from the buried active site of $D f$ NiFe hydrogenase. ${ }^{10}$ Substituting Leu122 and Val74, which shape a bottleneck in the channel (fig. 1a), strongly decreases the rates of intramolecular transport of $\mathrm{H}_{2}, \mathrm{CO}$ and $\mathrm{O}_{2}$ in both directions. 4,5 The decrease of the $\mathrm{H}_{2}$-binding bimolecular rate constant has no effect on the maximal rate of $\mathrm{H}_{2}$ oxidation obtained by extrapolation to infinite concentration of $\mathrm{H}_{2} .5$ Furthermore, the mutations considered below moderately increase the Michaelis constant for $\mathrm{H}_{2}$ (5 to 30 -fold for L122F-V74I and $\mathrm{V}_{74} \mathrm{M}$, respectively), but the Michaelis constant is small in the WT (about 10 matm of $\mathrm{H}_{2}$ ) and these mutations decrease less than 2-fold the $\mathrm{H}_{2}$ oxidation rate under one atm. of $\mathrm{H}_{2} .{ }^{5}$ Hence, substrate binding does not limit $\mathrm{H}_{2}$ oxidation under $1 \mathrm{~atm}$. of $\mathrm{H}_{2}$ in the WT and in these mutants.

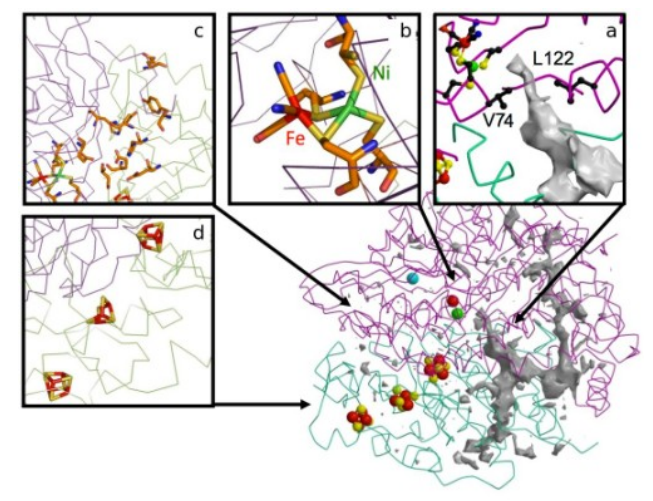

Figure 1. The structure of $D f \mathrm{NiFe}$ hydrogenase (pdb accession code: $1 Y Q W$ ). Close-ups show the structural elements that are involved in the catalytic cycle: the gas channel (a), the active site (b), a chain of aminoacids that are putatively involved in proton transfer (c), and the FeS clusters that wire the active site to the redox partner (d).

Figure 2 compares electrochemical signals obtained with the WT enzyme and two mutants (L122F-V74I and $\mathrm{V} 74 \mathrm{M}$, pdb $3 \mathrm{CUS}$ and $3 \mathrm{H}_{3} \mathrm{X}$ ) attached to rotating-disc graphite electrodes.7,8,11 Hydrogen oxidation and production are detected as positive and negative currents in a single experiment where the electrode potential is swept across a wide range. The absolute magnitude of the current is meaningless because it is proportional to turnover rate times the unknown electroactive coverage, but figure 2 clearly shows that the mutations decrease the ratio of oxidation over reduction currents: unlike the WT, the mutants are biased towards $\mathrm{H}_{2}$ oxidation. This illustrates that the term "bias" does not refer to "the direction of the reaction", which is imposed by thermodynamics, but to the ratio of rates (here, currents) measured for the same reaction proceeding in opposite directions. Since the conditions chosen for the two measurements are different, the ratio of rates is not an equilibrium constant. ${ }^{12}$ In electrochemical experiments, thermodynamics only forces the "open circuit potential" (OCP) to equate the reduction potential of the $\mathrm{H}^{+} / \mathrm{H}_{2}$ couple given by the Nernst equation; it is indeed independent of the enzyme (fig 2). 8,11

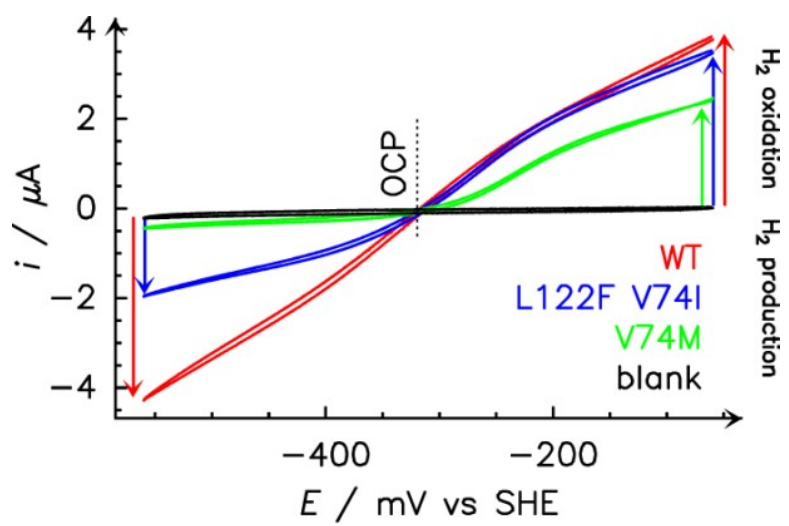

Figure 2. Bidirectional electrocatalysis by the WT (red), L122F-V74I (blue) and V74M (green) forms of $D f$ NiFe hydrogenase. The conditions $\left(10 \% \mathrm{H}_{2}, \mathrm{pH} 5.5,40^{\circ} \mathrm{C}\right.$, scan rate $10 \mathrm{mV} / \mathrm{s}$, electrode rotation rate $3 \mathrm{krpm}$ ) ensure that $\mathrm{H}_{2}$ oxidation (at high electrode potential) and production (at low potential) are detected in the same experiment. At the open circuit potential (OCP), the rates of oxidation and reduction exactly cancel each other. The blank was recorded with no adsorbed enzyme.

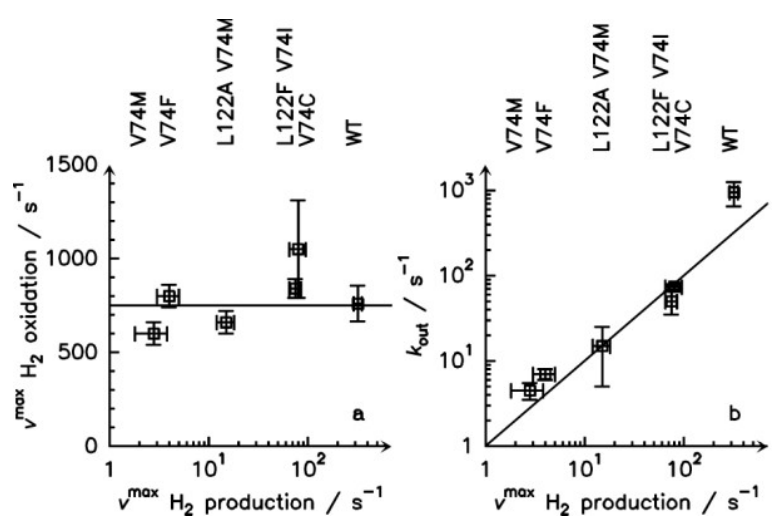

Figure 3. Kinetic properties of the hydrogenase channel mutants. Panel a shows the maximal rate of $\mathrm{H}_{2}$ oxidation plotted against the maximal rate of $\mathrm{H}_{2}$ production for 6 forms of the enzyme, and demonstrates that the mutants are biased towards $\mathrm{H}_{2}$ oxidation. Panel b shows the rates of $\mathrm{H}_{2}$ release (measured using eq 1 from experiments such as those in fig 4) against the maximal rates of $\mathrm{H}_{2}$ production, and demonstrates that the former limits the latter.

The results of solution assays with oxidized or reduced methyl viologen (MV) quantify the bias of the mutants. Figure 3a shows the maximal rates of $\mathrm{H}_{2}$ against the maximal rates of $\mathrm{H}_{2}$ production. The mutants have the same oxidation activity as the WT (only V74C is slightly more active 9 ) whereas their maximal $\mathrm{H}_{2}$ production rates vary by two orders of magnitude. The ratio of maximal rates (oxidation over production) ranges from 2.5 for the WT to 200 for the V74M mutant. Note that the exact val- 
ue of this bias is not an intrinsic property of the enzyme: it depends on which reaction is catalyzed (it is not the same for hydrogenase exchanging electrons with MV, an electrode, or its physiological partner), and on the conditions that are chosen to measure the two rates.

Table 1. Redox properties of the WT enzyme and two mutants. Ni-A, Ni-B and Ni-SU are inactive forms of the enzyme, whereas $\mathrm{Ni}-\mathrm{SI}, \mathrm{Ni}-\mathrm{C}$ and $\mathrm{Ni}-\mathrm{R}$ are catalytic intermediates. ${ }^{13}$ All reduction potentials are in $\mathrm{mV}$ vs SHE. Typical errors are $\pm 15 \mathrm{mV}$.

\begin{tabular}{|c|c|c|c|c|}
\hline $\begin{array}{l}\text { En- } \\
\text { zyme }\end{array}$ & $\begin{array}{l}\text { Ni-A/ } \\
\text { Ni-SU }\end{array}$ & $\begin{array}{l}\text { Ni-B/ } \\
\text { Ni-SI }\end{array}$ & $\begin{array}{l}\text { Ni-SI/ } \\
\text { Ni-C }\end{array}$ & $\begin{array}{l}\text { Ni-C/ } \\
\text { Ni-R }\end{array}$ \\
\hline WT & -195 & -175 & -330 & -430 \\
\hline V74M & -210 & -200 & -320 & -440 \\
\hline V74C & -175 & -135 & -370 & -450 \\
\hline
\end{tabular}

To examine whether the decrease in $\mathrm{H}_{2}$ production activity was due to a mutation-induced increase in the reduction potential of the active site, we compared the redox properties of the active site in the WT enzyme and the $\mathrm{V}_{74 \mathrm{C}}$ and $\mathrm{V} 74 \mathrm{M}$ mutants. Redox titrations of the active site states of wild type hydrogenase and the mutants V74M and V74C were monitored by FTIR in a spectroelectrochemical cell as described before. 9 The FTIR signatures of these mutants are similar to those of the WT enzyme. Supplementary fig. S1 shows the redox titration of the $\mathrm{CO}$ band of the Ni-C state for the three hydrogenases, from which the reduction potentials of the active site catalytic intermediates could be determined. Table 1 shows the formal reduction potentials of all the active site states. All results are similar, which suggests that the low reductive activities of the mutants are not the consequence of the potential of the active site being shifted upward compared to the WT value.

In search of the rate limiting step of $\mathrm{H}_{2}$ production, we determined the rate constants of $\mathrm{H}_{2}$ release, under the same conditions as $\mathrm{H}_{2}$ production, using the isotope exchange assay, where the enzyme transforms $\mathrm{D}_{2}$ into $\mathrm{HD}$ and eventually $\mathrm{H}_{2}$ using protons from the solvent. 4 The reaction is followed using mass spectrometry (fig 4). Assuming that all diatomic molecules diffuse to the active site with a bimolecular rate constant $k_{\text {in }}$ and from the active site with a 1st-order rate constant $k_{\text {out, }}$ and that $\mathrm{H}^{+} / \mathrm{D}^{+}$exchange at the active site proceeds with a 1storder rate constant $k$, we predicted 3 that both the concentration of $\mathrm{D}_{2}$ and the isotope content $T=\left[\mathrm{D}_{2}\right]+[\mathrm{HD}] / 2$ should decrease exponentially with time, as observed in figure 4 , with rates $k_{\mathrm{D}}$ and $k_{\mathrm{T}}$, respectively, which depend on $k_{\text {in }}, k_{\text {out }}, k, e_{\mathrm{o}}$ (the enzyme concentration) and $c_{\mathrm{o}}$ (the initial concentration of $\mathrm{D}_{2}$ ). The analysis that we previously reported allowed the determination of only the ratio $k_{\text {out }} / k$ (ref 4 ). We now show in supplementary information that under certain conditions, which apply to the case of $D f \mathrm{NiFe}$ hydrogenase, the rate of $\mathrm{H}_{2}$ release $k_{\text {out }}$ can be deduced from the data using eq. 1 :

$$
k_{\text {out }}=\frac{k_{D} k_{T}}{2 k_{T}-k_{D}} \frac{c_{0}}{e_{0}}
$$

When $k_{\text {out }} / k$ is small, little HD is released, $k_{\mathrm{D}} \approx k_{\mathrm{T}}$ (fig $4 \mathrm{~b})$, and $k_{\text {out }} \approx k_{\mathrm{D}} c_{\mathrm{o}} / e_{\mathrm{o}}$.
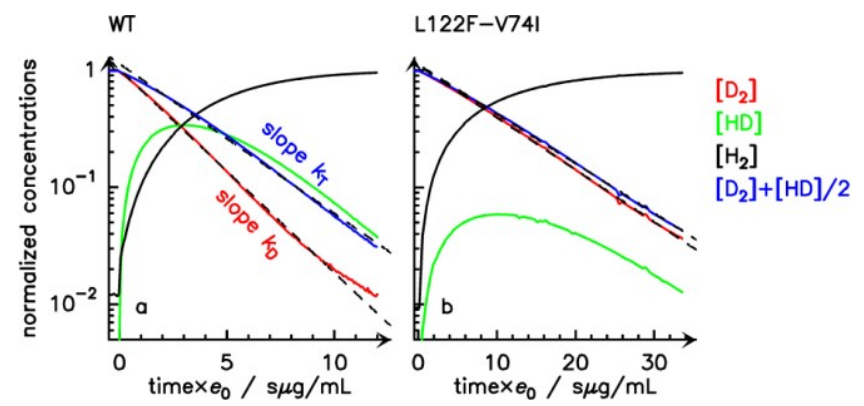

Figure 4. Isotope-exchange assay of the WT (Panel a) and L122F-V74I mutant (Panel b). The changes in concentrations were used to determine $k_{\text {out }}$ using eq. 1

We used this method with all above mentioned mutants to determine the rates of release of $\mathrm{H}_{2}\left(k_{\text {out }}\right)$, which we plotted against the maximal rate of $\mathrm{H}_{2}$ production in fig $3 \mathrm{~b}$ (note the log-log scale). All data points are close to the $y=x$ line, demonstrating that $\mathrm{H}_{2}$ production is limited by $\mathrm{H}_{2}$ release from the active site: the mutants have little production activity because the channel is obstructed, and $\mathrm{H}_{2}$-diffusion also determines the rate of $\mathrm{H}_{2}$ production in the WT enzyme.

Conversely, we previously made the same enzyme a better catalyst of $\mathrm{H}_{2}$ production than $\mathrm{H}_{2}$ oxidation by modifying its ET chain. ${ }^{6}$ The enzyme has a series of three FeS clusters, which "wires" the active site to the enzyme's redox partner (fig 1). The surface-exposed (distal from the active site) [4Fe4S] cluster is coordinated by His184; replacement with Gly184 or Cys184 slows $\mathrm{H}_{2}$ oxidation 33 and 6o-fold, respectively, whereas the rates of $\mathrm{H}_{2}$ production decrease only 1.3 and 2.1-fold (Table 1 in ref $6)$. These mutants are biased towards $\mathrm{H}_{2}$ production: both mutations decrease the ratios of maximal rates (oxidation over production) by a factor of about 27. The H184G mutant has an open coordination site on one Fe ion of the distal cluster; when exogenous imidazole binds to this cluster, the $\mathrm{H}_{2}$-oxidation rate increases from $3 \%$ to $33 \%$ of that of the WT, whereas the $\mathrm{H}_{2}$-production rate is not affected 6 : binding of imidazole to the distal cluster of $\mathrm{H} 184 \mathrm{G}$ partially repairs the ET chain and restores the native catalytic bias. It has long been suggested that ET limits the rate of $\mathrm{H}_{2}$-oxidation in WT NiFe-hydrogenase ${ }^{14}$ and this was recently supported by measurements of ET rates in the enzyme from $D$. fructosovorans. ${ }^{15}$ That a modification of the distal cluster biases the enzyme in the direction of $\mathrm{H}_{2}$ production shows that ET is rate limiting only for $\mathrm{H}_{2}$-oxidation.

Regarding the WT and mutant hydrogenases discussed here, our data show that $\mathrm{H}_{2}$-diffusion in the gas channel is the rate limiting step of $\mathrm{H}_{2}$-production but not $\mathrm{H}_{2}$ oxidation, whereas the latter is limited by electron transfer. Altering one of these steps selectively affects one of the two reactions. We therefore evidence a novel mechanism for tuning the catalytic bias of an oxidoreductase which is independent of the properties of the active 
site, but requires that the rls be different under the two different sets of conditions that are used to drive catalysis in one direction and the reverse. This contrasts with all previous explanations of the catalytic bias of oxidoreductases (see examples in supplementary information) which proposed that it may be determined by the redox properties of the cofactor(s).

The above results, and previous evidences that enzymes' turnover rates may be limited by steps other than active site chemistry (e.g. proton transfer, electron transfer, substrate release or lid-opening ${ }^{16}$ ), emphasize the need to study all steps of the reaction rather than only active site chemistry. Identifying the rls in a catalytic reaction, keeping in mind that active site chemistry may be fast, is a difficult task. Yet this is a prerequisite if one aims at understanding global kinetic properties, such as rate enhancement, proficiency, or bias.

Hydrogenases could be used as $\mathrm{H}_{2}$ oxidation or production catalysts in biotechnological devices ${ }^{17}$ if the enzymes that can be produced in large amounts were not inhibited by $\mathrm{O}_{2}$. This has motivated research on the inhibition mechanism, and $D f$ NiFe hydrogenase mutants that proved more resistant to $\mathrm{O}_{2}$ than the WT enzyme have been characterized; this includes the $\mathrm{V}_{74} \mathrm{C}$ and V74M mutants studied here.9,18 That mutations which increase $\mathrm{O}_{2}$ tolerance may also change the catalytic bias of the enzyme will have to be considered in studies which aim at optimizing this biological catalyst.

\section{ASSOCIATED CONTENT}

Complete references 4-6,9,15,18; examples of discussions in the literature of what may determine the bias of oxidoreductases ; demonstration of eq 1 ; redox titration curves of the WT and the $\mathrm{V} 74 \mathrm{C}$ and $\mathrm{V} 74 \mathrm{M}$ mutants. This material is available free of charge via the Internet at http://pubs.acs.org.

\section{AUTHOR INFORMATION}

\section{Corresponding Author}

christophe.leger@imm.cnrs-mrs.fr, laurent.cournac@ird.fr

\section{Present Addresses}

Laurent Cournac: IRD, UMR Eco\&Sols, 2 Place Viala, 34060 Montpellier Cedex 02, France.

\section{Author Contributions}

AAH, SD and PPL purified the proteins. AAH carried out the electrochemical experiments. AAH, SD, PR and LC carried out all solution assays and analyzed the data. OG and AdL carried out the spectro-electrochemical titrations. PB, LC, MR and CL initiated research. PB, SD and CL wrote the paper. All authors have given approval to the final version of the manuscript.

\section{Funding Sources}

Our work is funded by the CNRS, CEA, Aix-Marseille Université, ANR, City of Marseilles and Région Provence Alpes Cote d'Azur (PACA) and the Spanish Ministerio de Ciencia (Project CTQ2009-12649). We acknowledge support from the "Pole de compétitivité Capénergie". AAH thanks the CNRS and Region PACA for funding his PhD.

\section{REFERENCES}

[1] (a) Terrell, L. Hill. "Free Energy Transduction in Biology, The Steady State Kinetic and Thermodynamic Formalism," Academic Press, 1977. ISBN 0-12-348250-X.

(b) Alberty, R. A., J. Am. Chem. Soc. 1953, 75, 1928-1932.

[2] Jencks, W. P., Adv Enzymol. Relat. Areas Mol. Biol. 1975, 43, 219-410.

[3] Warshel, A.; Florián, J.; Strajbl, M.; Villà, J., Chembiochem. 2001, 2, 109-111.

[4] Leroux, F. et al., Proc Natl Acad Sci USA. 2008, 105, 11188-11193.

[5] Liebgott, P.P. et al., Nat Chem Biol. 2010, 6, 63-70.

[6] Dementin, S. et al., J Am Chem Soc. 2006 128, 5209-5218.

[7] Rüdiger, O.; Abad, J. M. ; Hatchikian, E. C. ; Fernandez, V. M.; De Lacey, A. L., J Am Chem Soc. 2005; 127, 16008-16009.

[8] Léger, C.; Dementin, S.; Bertrand, P.; Rousset, M.; Guigliarelli, B.; J Am Chem Soc. 2004, 126, 12162-12172.

[9] Liebgott, P.P. et al., J Am Chem Soc. 2011, 133, 986-997.

[10] (a) Montet, Y.; Amara, P.; Volbeda, A.; Vernede, X.; Atchikian, E.C.; Field, M. J.; Frey, M.; Fontecilla-Camps, J.-C. Nat. Struct. Biol. 1997, 4, 523-526.

(b) Wang, P. H.; Best, R.B.; Blumberger, J., J. Am. Chem. Soc, 2011, 133, 3548-3556.

[11] Léger, C.; Bertrand, P. Chem Rev. 20o8, 108, 2379-2438.

[12] Blackmond, D. G., Angew. Chem. Int. Ed. Engl. 2009, 48, 2648-2654

[13] De Lacey, A.L.; Fernandez, V.M.; Rousset, M.; Cammack, R.; Chem. Rev 2007, 107, 4304-4330.

[14] Pershad, H.R.; Duff, J. L.; Heering, H. A.; Duin, E.C.; Albracht, S. P.; Armstrong, F. A., Biochemistry, 1999, 38, 89928999.

[15] Dementin, S. et al., J Am Chem Soc. 2011, 133, 1021110221.

[16] (a) Mikulski, R.L.; Silverman, D. N. Biochim Biophys Acta. 2010, 1804, 422-426.

(b) Hay, S.; Brenner, S.; Khara, B.; Quinn, A. M.; Rigby, S. E. ; Scrutton, N. S.; J Am Chem Soc. 2010, 132, 9738-9745.

(c) Tegoni, M.; Silvestrini, M. C.; Guigliarelli, B.; Asso, M.; Brunori, M.; Bertrand, P., Biochemistry. 1998; 37, 12761-12771.

(d) Fierke, C. A.; Johnson, K. A.; Benkovic, S. J.; Biochemistry 1987, 26, 4085-4092.

(e) Wolf-Watz, M.; Thai, V.; Henzler-Wildman, K.; Hadjipavlou, G.; Eisenmesser, E. Z.; Kern, D., Nat. Struct. Mol. Biol. 2004, 11, 945-949.

[17] (a) Cracknell, J. A.; Vincent, K. A., Ludwig, M.; Lenz, O.; Friedrich, B.; Armstrong, F. A., J Am Chem Soc 2007 13O, 424425.

(b) Hambourger, M.; Gervaldo, M.; Svedruzic, D.; King, P.W.; Gust, D.; Ghirardi, M.; Moore, A. L.; Moore, T. A., J Am Chem Soc, 2008, 13O, 2015-2022.

[18] Dementin, S. et al., J. Am. Chem. Soc. 2oo9, 131, 1015610164 . 